Citation: M. I. Drais, E. Pannucci, R. Caracciolo, R. Bernini, A. Romani, L. Santi, L. Varvaro (2021) Antifungal activity of hydroxytyrosol enriched extracts from olive mill waste against Verticillium dahliae, the cause of Verticillium wilt of olive. Phytopathologia Mediterranea 60(1): 139-147. doi: 10.36253/ phyto-12019

Accepted: January 5, 2021

Published: May 15, 2021

Copyright: $\odot 2021$ M. I. Drais, E. Pannucci, R. Caracciolo, R. Bernini, A. Romani, L. Santi, L. Varvaro. This is an open access, peer-reviewed article published by Firenze University Press (http:// www.fupress.com/pm) and distributed under the terms of the Creative Commons Attribution License, which permits unrestricted use, distribution, and reproduction in any medium, provided the original author and source are credited.

Data Availability Statement: All relevant data are within the paper and its Supporting Information files.

Competing Interests: The Author(s) declare(s) no conflict of interest.

Editor: Epaminondas Paplomatas, Agricultural University of Athens, Greece.
Research Papers

\section{Antifungal activity of hydroxytyrosol enriched extracts from olive mill waste against Verticillium dahliae, the cause of Verticillium wilt of olive}

\author{
Mounira InAS DRAIS ${ }^{1, *}$, Elisa PANNUCCI ${ }^{1}$, Rocco CARACCIOLO ${ }^{1}$, \\ Roberta BERNiNi ${ }^{1}$, AnNAlisa ROMANI ${ }^{2}$, LucA SANTI ${ }^{1}$, LeONARdo \\ VARVARO $^{1, *}$ \\ ${ }^{1}$ Department of Agriculture and Forest Sciences, University of Tuscia, Via S. Camillo de \\ Lellis snc, Viterbo, Italy \\ ${ }^{2}$ Department of Statistics, Computing, Applications "Giuseppe Parenti" DiSIA, PHYTO- \\ LAB (Pharmaceutical, Cosmetic, Food supplement Technology and Analysis), University \\ of Florence, Florence, Italy \\ ^Corresponding authors. E-mail: drais@unitus.it, varvaro@unitus.it
}

\begin{abstract}
Summary. Verticillium wilt (caused by Verticillium dahliae Kleb.) is an important disease affecting olive (Olea europaea L.) production. Effective control of this disease relies on integrated management strategies. In vitro antifungal activity of two hydroxytyrosol (HTyr) enriched extracts (HTE1 and HTE2) obtained from olive mill waste products (OMWP) was assessed against $V$. dahliae. Inhibitory effects of pure HTyr as a standard, and HTE1 and HTE2 at different concentrations, were evaluated on mycelium growth and conidium germination of $V$. dahliae. Chemical characterization of HTE1 and HTE2 allowed identification and quantification of HTyr as the main constituent in both extracts along with other low molecular weight phenols. HTE1 showed a higher inhibitory activity in both growth and conidium germination of $V$. dahliae. At the tested concentrations, low antifungal effects of HTyr were observed. After $3 \mathrm{~d}$, $1 \mathrm{mg} \mathrm{mL} \mathrm{m}^{-1}$ of HTE1 gave greater inhibition of mycelium growth than HTE2 or HTyr. After $24 \mathrm{~h}$, HTE1 gave 55\% inhibition of conidium germination, and HTyr and HTE2 both gave $37 \%$ inhibition. This study has demonstrated that phenolic compounds derived from OMWP have antifungal activity against $V$. dahliae, indicating the potential of these compounds for eco-friendly control of Verticillium wilt.
\end{abstract}

Keywords. Olea europaea, enriched extracts, phenolic compounds, fungus inhibition.

\section{INTRODUCTION}

Verticillium wilt, caused by Verticillium dahliae, severely affects olive trees (Olea europaea L.), causing economic losses due to plant death (Jiménez-Díaz et al., 1998; López-Escudero and Mercado-Blanco, 2011). The soilborne fungus is considered one of the most serious threats to olive fruit and 
oil production, and the disease is widely distributed in all Mediterranean olive-growing regions (Jiménez-Díaz et al., 2012). Olive trees are highly sectored with direct vascular connections of specific roots and shoots (Lavee et al., 1996). Verticillium dahliae infects host plants through their roots, and colonizes vascular systems, blocking water flow and eventually inducing wilt symptoms (Van Alfen, 1989). This damage results in significant reductions of leaf transpiration, which lead to leaf chlorosis and defoliation. Severe attacks cause trees to eventually die.

Since no control measures have proved to be successful when individually employed, an integrated strategy is recommended for management of Verticillium wilt of olive (VWO) (López-Escudero and Mercado-Blanco, 2011). Several studies have reported the use of antagonistic microorganisms as biological control agents (BCAs) against $V$. dahliae in olive (Mercado-Blanco et al., 2004; Triki et al., 2012; Markakis et al., 2016; Varo et al., 2016; Mulero-Aparicio et al., 2019). In addition, natural compounds could be complementary for integrated ecofriendly management of this important disease.

Beside the well-known antifungal activity of plant derived essential oils, which has been demonstrated for V. dahliae (López-Escudero et al., 2007; Varo et al., 2017), other classes of natural products also hold promise for disease management. Phenolic compounds have demonstrated, in parallel with strong antioxidant activity, antimicrobial activity in general and antifungal activity in particular (Yangui et al., 2009; Pannucci et al., 2019). These compounds can be obtained from the waste products of olive oil production; the two most prominent of these compounds are oleuropein obtained from leaves, and hydroxytyrosol (HTyr) from drupes (Thielmann et al., 2017). For HTyr, recent studies have demonstrated bactericidal and fungicidal activities of olive mill waste products (OMWP) obtained by a proprietary, environmentally friendly membrane technology (Pannucci et al., 2019). Several studies have examined the phenolic components of OMWP for use as biopesticides for crop protection (Mekki et al., 2006a, 2006b, 2008; Yangui et al., 2008, 2010; Larif et al., 2013; Lykas et al., 2014). These components would also fulfil the criteria for a sustainable economic development (Romani et al., 2016; Bernini et al., 2017).

The present study evaluated the effectiveness of two HTyr-enriched extracts from OMWP against $V$. dahlia using pure HTyr as standard. In vitro inhibitory effects on mycelium growth and conidium germination of a $V$. dahliae isolate were assessed. The aim was to determine the potential for using these extracts as part of integrated management of VWO.

\section{MATERIALS AND METHODS}

\section{Plant extracts}

Two HTyr enriched extracts (HTE1 and HTE2) were used. HTE1 was obtained from olive oil waste water (from olive cultivars 'Coratina' and 'Leccino'), collected from Molfetta (Puglia, Italy; $41^{\circ} 31^{\prime} 42.8^{\prime \prime} \mathrm{N}, 12^{\circ} 47^{\prime} 31.3^{\prime \prime} \mathrm{E}$ ) in January 2017, using a previously described procedure (Pizzichini et al., 2011; Romani et al., 2016; Bernini et al., 2017; Pannucci et al., 2019). HTE2 was prepared from olive pomace (from cultivar 'Leccino') from Catania (Sicily, Italy; $37^{\circ} 29^{\prime} 32^{\prime \prime} \mathrm{N}, 15^{\circ} 4^{\prime} 13^{\prime \prime} \mathrm{E}$ ) in January 2017 , using the following procedure (Romani et al., 2016; Bernini et al., 2017). After olive oil production, the olives were de-oiled and pitted to obtain a pulp. This material was acidified to $\mathrm{pH}=2.5-4.0$, and then extracted at room temperature with an aqueous solvent using an electrical pneumatic extractor. The resulting solution was filtered by microfiltration, ultrafiltration, and nanofiltration. After a reverse osmosis step, the resulting fraction was concentrated under vacuum by using a scraper evaporator series (C \& G Depurazione Industriale Company) combined with a heat pump (Romani et al., 2016; Bernini et al., 2017).

\section{Chemicals}

All solvents and chemical used for extractions were of the highest analytical grade (Sigma-Aldrich). Pure HTyr used as standard in experiments was synthetized to purity $>98 \%$, using a proprietary procedure (Bernini et al., 2008; 2010).

\section{Characterization of HTE1 and HTE2}

HTE1 and HTE2 were characterized using High Performance Liquid Chromatography/Diode Array Detector (HPLC/DAD) and Nuclear Magnetic Resonance $\left({ }^{1} \mathrm{H}\right.$ NMR), and the analytical profiles were compared with HTyr. The HPLC/DAD analyses were carried out using an HP 1200 liquid chromatograph (Agilent Technologies), equipped with an analytical column (Lichrosorb $\mathrm{RP} 18250 \times 4.60 \mathrm{~mm}$ i.d, $5 \mu \mathrm{m}$; Merck). The eluents were $\mathrm{H}_{2} \mathrm{O}$ adjusted to $\mathrm{pH}=3.2$ with $\mathrm{HCOOH}$ (solvent $\mathrm{A}$ ) and $\mathrm{CH}_{3} \mathrm{CN}$ (solvent B). A four-step linear solvent gradient was used, starting from $100 \%$ of solvent A up to $100 \%$ of solvent $\mathrm{B}$, for $88 \mathrm{~min}$ at a flow rate of $0.8 \mathrm{~mL} \mathrm{\textrm {min } ^ { - 1 }}$ (Romani et al., 2016; Bernini et al., 2017). Phenolic compounds found in the extracts were identified by comparing retention times and UV/Vis spectra with those of the 


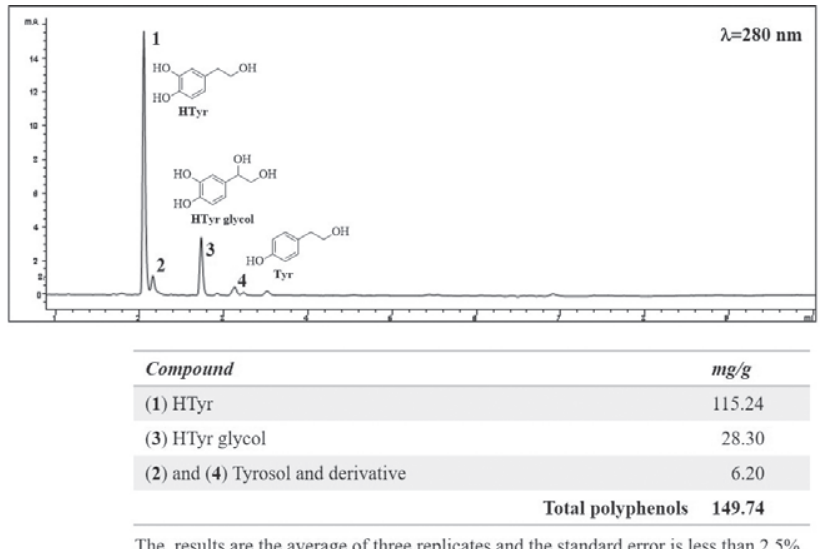

Figure 1. HPLC/DAD chromatographic profile of HTE2 at $280 \mathrm{~nm}$.

authentic standards. Each compound was characterized using a five-point regression curve built with the available standards. Analytical data are reported in Figure 1.

${ }^{1} \mathrm{H}$ NMR spectra were recorded using a $400 \mathrm{MHz}$ Nuclear Magnetic Resonance Spectrometer Avance III (Bruker). Chemical shifts were expressed in parts per million ( $\delta$ scale) and referred to the residual protons of the solvent. Samples were prepared solubilizing 20-30 $\mathrm{mg}$ of each sample in methanol-d4. NMR spectra are shown in Figure 2.

a

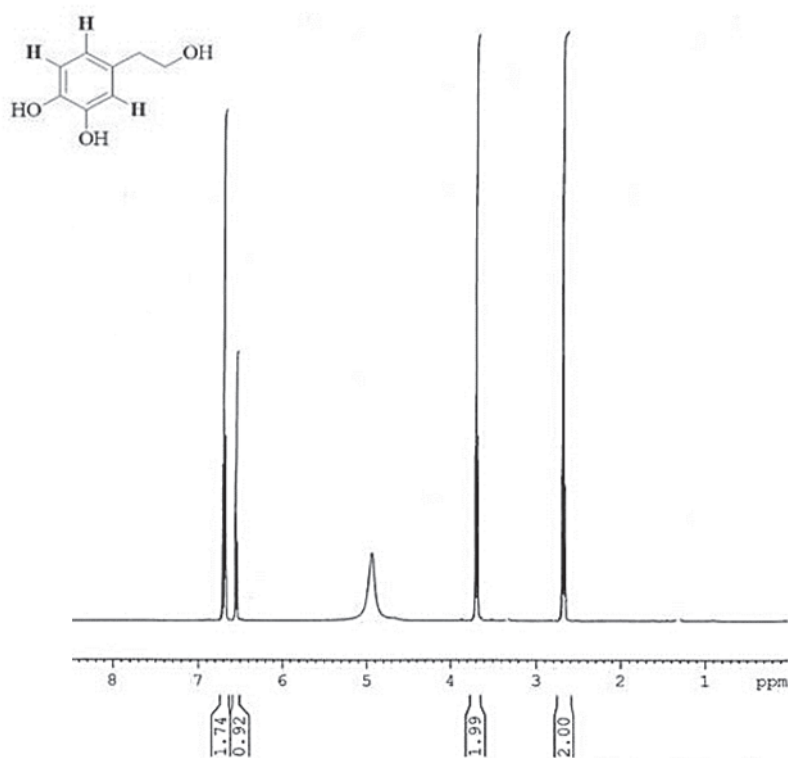

Figure 2. ${ }^{1} \mathrm{H}-\mathrm{NMR}$ spectra of HTyr (a) and HTE2 (b).
Table 1. Fungi and strains used for the preliminary screening.

\begin{tabular}{lcl}
\hline Fungi & Strain & \multicolumn{1}{c}{ Collection } \\
\hline $\begin{array}{l}\text { Verticillium dahliae } \\
\text { Botrytis cinerea }\end{array}$ & VD22 & $\begin{array}{l}\text { Laboratory of plant } \\
\text { pathology of DAFNE } \\
\text { department, Tuscia } \\
\text { University. }\end{array}$ \\
$\begin{array}{l}\text { Fusarium graminearum } \\
\text { Fusarium culmorum } \\
\begin{array}{l}\text { Septoria tritici } \\
\text { Bipolaris sorokiniana }\end{array}\end{array}$ & $\begin{array}{l}\text { MU27 } \\
\text { MUCL 31967 }\end{array}$ & $\begin{array}{l}\text { Laboratory of Plant } \\
\text { pathology of the Department } \\
\text { of Land, Environment, } \\
\text { Agriculture and Forestry of } \\
\text { Padova University. }\end{array}$ \\
\hline
\end{tabular}

Preliminary activity screening using HTyr against selected fungus isolates

Six fungus isolates were used (Table 1). Synthesized HTyr was used as standard for preliminary testing effects on the fungi, and to identify an active concentration of the compound to be used as reference for comparisons with HTE1 and HTE2. Verticillium dahliae and $B$. sorokiniana were inhibited by HTyr. The V. dahliae pathogen from olive was selected and additional tests were carried out to confirm the antifungal activity of HTyr and the two extracts. The other fungus isolates showed high variability and low susceptibility to the compounds and were not investigated further.

b

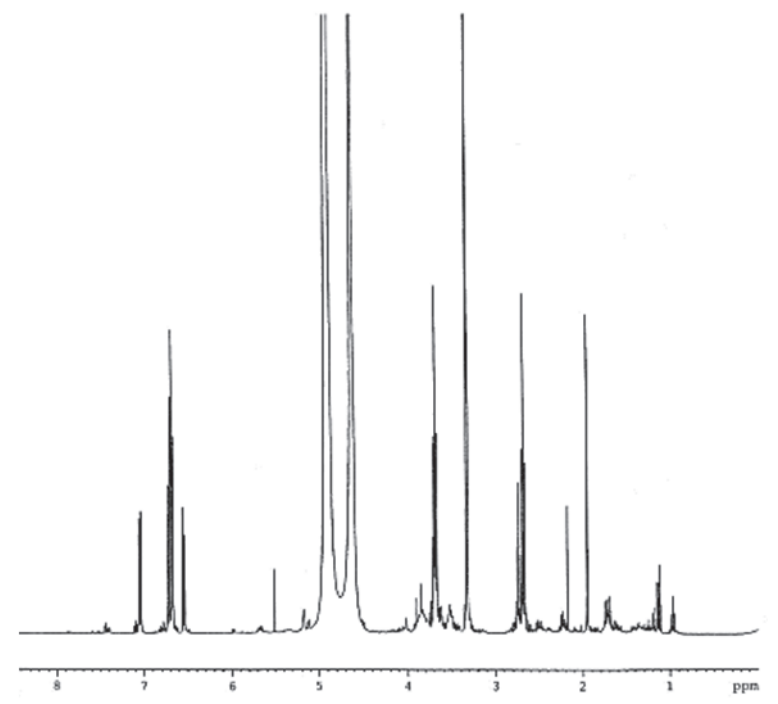


Antifungal activity of HTyr, HTE1 or HTE2 on mycelium growth of Verticillium dahliae

The V. dahliae isolate VD 22 was grown on Potato dextrose Agar (PDA) for $7 \mathrm{~d}$ at $25^{\circ} \mathrm{C}$ before conducting the following experiments:

Disc diffusion assays. These were used to evaluate the antifungal activity of the HTyr standard against the $V$. dahliae isolate. The antifungal test was carried out by placing a mycelium plug in the centre of each PDA Petri dish, and at $3 \mathrm{~cm}$ from a paper disk (Oxoid) to which 1 mg of HTyr had been applied. After $72 \mathrm{~h}$ incubation at $25^{\circ} \mathrm{C}$, the distance $(\mathrm{mm})$ between the edge of the resulting fungus mycelium and the edge of the disk was measured (Balouiri et al., 2016). Data are expressed as means of three independent replicas per treatment.

Modified top agar assays. These were used to evaluate the antifungal activity of HTyr, HTE1 and HTE2 obtained from OMWP against $V$. dahliae. HTyr was tested at concentrations of $0.25,0.5$ or $1 \mathrm{mg} \mathrm{mL}^{-1}$. HTE1 was tested at 7.6, 15.2 or $30.4 \mathrm{mg} \mathrm{mL}^{-1}$, and HTE2 was tested at $2.15,4.3$ or $8.6 \mathrm{mg} \mathrm{mL}^{-1}$. These concentrations correspond to $0.25,0.5$ or $1 \mathrm{mg} \mathrm{mL}^{-1}$ of the corresponding HTyr content for each extract. The Top Agar was obtained by incorporating HTyr or the extracts at different concentrations into a final volume of $5 \mathrm{~mL}$ of PDA. The substrate obtained was poured into Petri dishes on top of $20 \mathrm{~mL}$ of previous solidified PDA. Solidified Top Agar was inoculated in the centre of each Petri dish with a mycelium plug of the $V$. dahliae isolate. Negative experimental controls were prepared by replacing the volume of samples with the same volume of sterile distilled water.
At 3, 5 and 7 days post-inoculation the diameter of mycelium growth in each Petri dish was measured (Figure 3), and these data were subsequently analyzed to calculate the percentage of mycelium growth inhibition (MGI\%), using the following formula:

MGI \% $=[(\mathrm{C}-\mathrm{T}) / \mathrm{C}] \cdot 100$,

where $\mathrm{C}=$ diameter of mycelium growth in the experimental control, and $\mathrm{T}=$ diameter of mycelium growth treated with HTyr or the extracts.

Antifungal activity of HTyr, HTE1 or HTE2 on Verticillium dahliae conidium germination

Effects of HTyr on conidium germination were evaluated by placing $5 \mu \mathrm{L}$ of $V$. dahliae conidium suspension $\left(10^{5}\right.$ conidia $\left.\mathrm{mL}^{-1}\right)$ on a thin layer of water agar on a glass microscope slide. The water agar amended with $1 \mathrm{mg} \mathrm{mL} \mathrm{m}^{-1}$ of HTyr, HTE1 or HTE2. The Microscope slides were placed in Petri dishes lined with moist filter papers $(100 \% \mathrm{RH}$.$) , and were incubated for 24 \mathrm{~h}$ at $25^{\circ} \mathrm{C}$. Germinated conidia were counted after $6 \mathrm{~h}$ and $24 \mathrm{~h}$, using a minimum of 100 conidia per replicate, with four replicates accessed (Khalil et al., 1985). The results were expressed as percentages of inhibition of germination in relation to experimental controls, as follows:

Percent inhibition $=[(\mathrm{C}-\mathrm{T}) / \mathrm{C}] 100$,

where $\mathrm{C}=$ conidium germination in the control, and $\mathrm{T}=$ conidium germination in treatment with HTyr or the extracts.

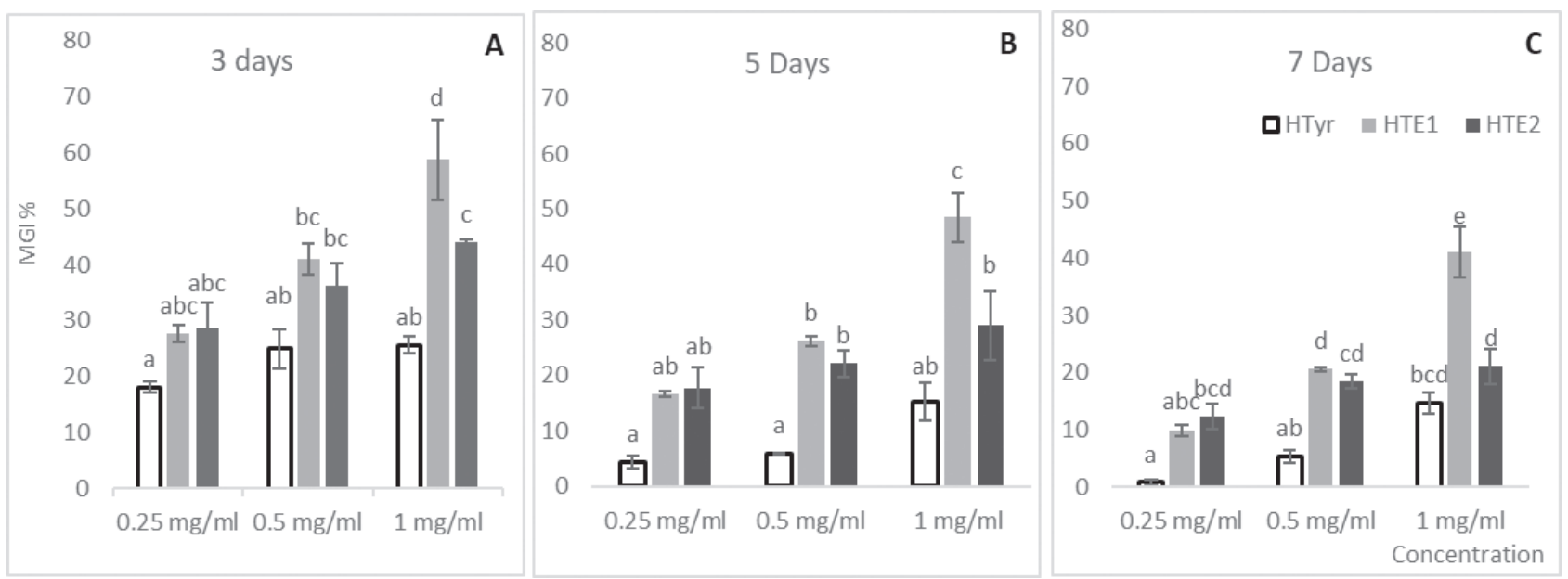

Figure 3. Verticillium dahliae mycelium growth inhibition percent (MGI \%) in top agar assays. The data for different concentrations of HTyr, HTE1 and HTE2 are presented for 3 (A), 5 (B) and 7 (C) d of incubation. Bars indicate standard errors of triplicates and different letters indicate differences $(P<0.05)$, according Tukey's (HSD) multiple range test. 


\section{Data analyses}

Differences (at $P<0.05$ ) between means of the parameters measured were determined by analysis of variance (ANOVA) and Tukey's (HSD) multiple range test. IBM SPSS Statistics for Windows, Version 22.0, was used for these statistical analyses.

\section{RESULTS}

\section{Phenolic profiles of HTE1 and HTE2}

The qualitative and quantitative HPLC profiles of HTE1 have been previously described by Pannucci et al. (2019). In this extract, the main compound found was HTyr at $32.83 \mathrm{mg} \mathrm{g}^{-1}$, representing the $64.7 \% \mathrm{w} / \mathrm{w}$ of the total phenols $\left(50.7 \mathrm{mg} \mathrm{g}^{-1}\right)$. Minor components in this extract were verbascoside ( $\left.12.9 \mathrm{mg} \mathrm{g}^{-1}, 25.4 \% \mathrm{w} / \mathrm{w}\right)$, tyrosol, gallic acid and verbascoside derivatives, which in total constituted the $9.6 \% \mathrm{w} / \mathrm{w}$ of total phenols.

This is the first description of HTE2. The chromatographic profile indicated that HTE2 contained $149.7 \mathrm{mg}$ $\mathrm{g}^{-1}$ of polyphenols. The main compound in the extract was HTyr (115.2 $\left.\mathrm{mg} \mathrm{g}^{-1}, 77 \% \mathrm{w} / \mathrm{w}\right)$, and the secondary components were HTyr glycol and tyrosol $\left(34.5 \mathrm{mg} \mathrm{g}^{-1}, 23 \% \mathrm{w} / \mathrm{w}\right)$.

The ${ }^{1} \mathrm{H}$ NMR spectrum of HTE2 confirmed the presence of HTyr as the main compound. The signals of the three aromatic protons $(\delta, \mathrm{ppm}: \mathrm{dd}, 6.53-6.56, \mathrm{~J}=8.0$ and $4.0 \mathrm{~Hz}, 1 \mathrm{H} ; \mathrm{d}, 6.67, J=4.0 \mathrm{~Hz}, 1 \mathrm{H} ; \mathrm{d}, 6.70, J=8.0$ $\mathrm{Hz}, 1 \mathrm{H}$ ) were superimposable with those of HTyr.

Effects of HTyr, HTE1 and HTE2 on the mycelium growth of Verticillium dahliae

After $3 \mathrm{~d}$ incubation, the ANOVA of $V$. dahliae mycelium growth data showed significant differences among the treatments (HTyr, HTE1 or HTE2), and the related extract concentrations $\left(0.25,0.5\right.$ or $\left.1 \mathrm{mg} \mathrm{mL}^{-1}\right)(\mathrm{F}(8,18)$ $=11.98, P<0.001)$. Tuckey HSD analysis showed that at the lowest concentration $\left(0.25 \mathrm{mg} \mathrm{mL}^{-1}\right)$ there was no statistically significant difference on the inhibition of the mycelium growth of $V$. dahliae between HTyr (mean $=18.1, \mathrm{SD}=1.77), \mathrm{HTE} 1($ mean $=27.7, \mathrm{SD}=2.66)$ and HTE2 (mean $=28.7, \mathrm{SD}=7.84$ ). Similarly, at $0.5 \mathrm{mg}$ $\mathrm{mL}^{-1}$, no significant difference in the inhibition of the pathogen was observed between HTyr (mean $=25.0$, $\mathrm{SD}=6.05)$, HTE1 $($ mean $=40.9, \mathrm{SD}=4.69)$ and HTE2 $($ mean $=36.1, \mathrm{SD}=7.23)$. At $1 \mathrm{mg} \mathrm{mL}^{-1}$, HTE1 (mean = $58.8, \mathrm{SD}=12.56)$ gave greater inhibition of $V$. dahliae than HTE2 $($ mean $=44.0, \mathrm{SD}=0.78)$ or HTyr $($ mean $=$ $25.6, \mathrm{SD}=2.67)$.
After $5 \mathrm{~d}$ incubation, significant differences in mycelium growth were detected among the treatments and their concentrations $(\mathrm{F}(8,18)=17.3, P<0.001)$. At 0.25 $\mathrm{mg} \mathrm{mL} \mathrm{m}^{-1}$ there was no significant difference between HTyr $($ mean $=4.3, \mathrm{SD}=2.08)$, HTE1 (mean $=16.6, \mathrm{SD}=$ $0.78)$ and HTE2 (mean $=17.7, \mathrm{SD}=6.50)$. Whereas at 0.5 $\mathrm{mg} \mathrm{mL}^{-1}$ (Figure 3), HTE1 (mean $=26.1, \mathrm{SD}=1.55$ ) and HTE2 (mean $=22.1, \mathrm{SD}=4.04)$ gave greater inhibition of mycelium growth than HTyr (mean $=5.9, \mathrm{SD}=0.07$ ). At $1 \mathrm{mg} \mathrm{mL}^{-1}$ of HTyr, HTE1 $($ mean $=48.5, \mathrm{SD}=7.72)$ gave greater inhibition of $V$. dahliae than HTyr (mean $=$ $15.2, \mathrm{SD}=5.88)$ and HTE2 $($ mean $=29.0, \mathrm{SD}=10.75)$.

After $7 \mathrm{~d}$ incubation, significant difference in mycelium growth were detected among treatments and their concentrations $(\mathrm{F}(8,18)=28.60, P<0.001)$. At $0.25 \mathrm{mg}$ $\mathrm{mL}^{-1}$, no significant differences were detected between the HTyr (mean $=0.8, \mathrm{SD}=0.72$ ) and HTE1 (mean $=9.9, \mathrm{SD}$ $=1.66$ ), or between HTE1 (mean $=9.9, \mathrm{SD}=1.66$ ) and HTE2 (mean $=12.3, \mathrm{SD}=3.71)$, but a significant difference was found between HTyr (mean $=0.8, \mathrm{SD}=0.72$ ) and HTE2 (mean $=12.3, \mathrm{SD}=3.71$ ). At $0.5 \mathrm{mg} \mathrm{mL}^{-1}$ differences in mycelium growth were detected between $\mathrm{HTyr}$ $($ mean $=5.3, \mathrm{SD}=2.08)$ and HTE1 $($ mean $=20.5, \mathrm{SD}=$ 0.73), and between HTyr and HTE2 (mean $=18.4$, SD = 2.05), but not between HTE1 (mean $=20.5, \mathrm{SD}=0.73$ ) and HTE2 (mean $=18.4, \mathrm{SD}=2.05$ ). At $1 \mathrm{mg} \mathrm{mL}^{-1}$, greater inhibition of $V$. dahliae was observed from HTE1 (mean $=41.0, \mathrm{SD}=7.74)$ compared to HTE2 $($ mean $=21.0, \mathrm{SD}=$ 5.50) and HTyr (mean $=14.69, \mathrm{SD}=3.26$ ), but no difference was measured between the effects of HTyr and HTE2.

For effects of different concentrations of each extract on growth of $V$. dahliae, from HTE1, after $3 \mathrm{~d}$, there was no difference between the $0.25 \mathrm{mg} \mathrm{mL}^{-1}$ (mean $=27.7$, SD $=2.66)$ and $0.5 \mathrm{mg} \mathrm{mL}^{-1}$ (mean $\left.=40.9, \mathrm{SD}=4.69\right)$ treatments, but a significant difference was detected between the $1 \mathrm{mg} \mathrm{mL}^{-1}($ mean $=58.7, \mathrm{SD}=12.56)$ and the 0.5 and $0.25 \mathrm{mg} \mathrm{mL}^{-1}$ treatments. Similarly, after 5 and $7 \mathrm{~d}$ of incubation, there was a difference in inhibition of $V$. dahliae from the greatest concentration of HTE1. For HTE2, there were no statistically significant differences in inhibition from the three different concentrations, after 3,5 or and $7 \mathrm{~d}$ incubation.

Effects of HTyr, HTE1 or HTE2 on conidium germination of Verticillium dahliae

After $6 \mathrm{~h}$ incubation, HTyr gave 88\% inhibition of conidium germination, while the two extracts caused greater inhibition, 99\% from HTE1 and 95\% from HTE2. After $24 \mathrm{~h}$ incubation, HTE1 gave the greatest inhibition (55\%), while HTyr and HTE2 both gave 37\% inhibition of conidium germination (Figure 4). 


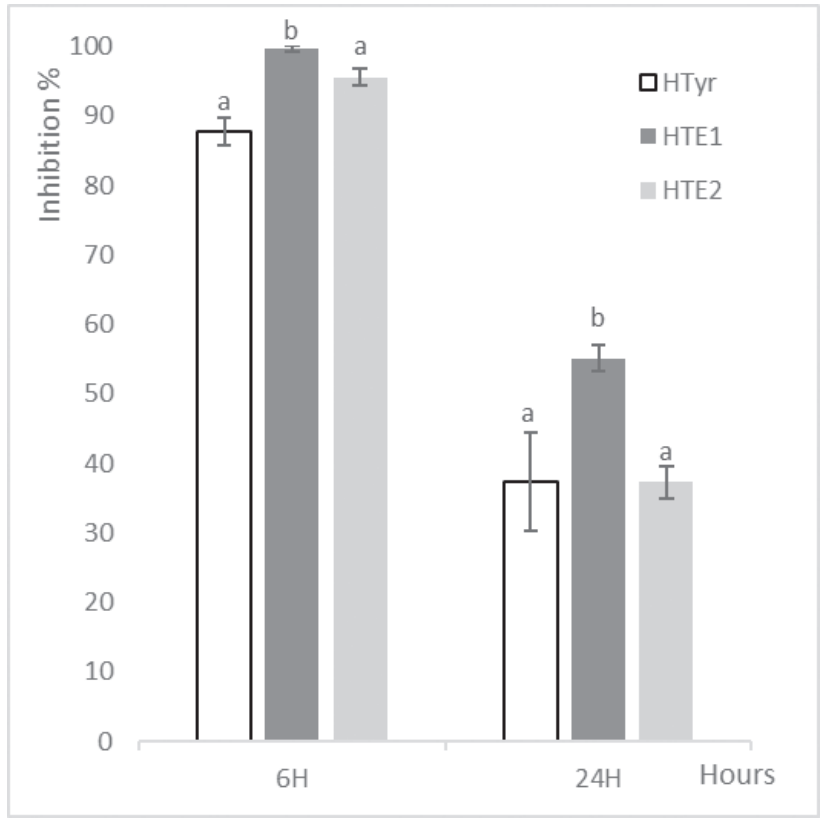

Figure 4. HTyr and HTE extracts mean inhibition (\%) on Verticillium dahliae conidium germination. HTyr standard was tested at 1 $\mathrm{mg} \mathrm{mL} \mathrm{m}^{-1}$ and HTE1 and HTE2 were tested at $1 \mathrm{mg} \mathrm{mL}^{-1}$ referred to the HTyr content in each extract. Germinated conidia were counted after 6 and $24 \mathrm{~h}$ incubation at $25^{\circ} \mathrm{C}$ in the dark, and means are for 100 conidia per replicate. Bars indicate standard errors, and different letters indicate significant differences $(P<0.05)$, Tukey's (HSD) multiple range test.

Statistically significant differences in inhibition of conidium germination were detected between the treatments with HTyr, HTE1 and HTE2 $(\mathrm{F}(5,18)=3.37, P$ $<0.05)$. Application of $1 \mathrm{mg} \mathrm{mL}^{-1}$ of HTyr or the two extracts gave differences in percent germination after $6 \mathrm{~h}$ incubation between HTE1 (mean $=99.6, \mathrm{SD}=0.71$ ) and HTE2 (mean $=95.5, \mathrm{SD}=2.31$ ) Similar differences were observed between the effects of HTyr (mean $=87.7$, SD = 3.82) and HTE1 (mean = 99.6, SD =0.71). After $24 \mathrm{~h}$ incubation, no differences were detected between HTE2 $($ mean $=37.3, \mathrm{SD}=4.54)$ and HTyr $($ mean $=37.3, \mathrm{SD}=$ 14.28). However, the difference between HTE1 (mean = 55.1, $\mathrm{SD}=3.95)$ and HTE2 (mean $=37.3, \mathrm{SD}=4.54)$ was indeed statistically significant.

\section{DISCUSSION}

The increasing interest of the use of natural products in agricultural includes research on plant derived compounds for pest and disease management. This aims to meet the regulatory demands for reduction in the use of synthetic pesticides, to provide environmentally friend- ly approaches. Several reports have described effects of plant extracts on fungal plant pathogens. Phenolic compounds derived from OMWP have been shown to hold promise as natural fungicides against crop pathogens, including Alternaria solani, Botrytis cinerea and Fusarium culmorum (Winkelhausen et al., 2005). In particular, HTyr is well-known and of interest to the pharmaceutical industry, because of the antioxidant, anti-inflammatory (Bernini et al., 2015) and antimicrobial properties (Robles-Almazan et al., 2018; Pannucci et al., 2019) of this compound. OMWP enriched in HTyr, is a resource for agricultural applications. We have evaluated HTE1 and HTE2, obtained by OMWP, through a sustainable pilot process (Romani et al., 2016; Bernini et al., 2017) based on membrane technologies which mainly enrich HTyr, together with other low molecular weight phenols, as has been shown using HPLC and NMR analyses.

In the present study, the capacities have been demonstrated for HTyr, HTE1 and HTE2 to affect mycelium growth and conidium germination of $V$. dahliae, the cause agent of Verticillium wilt of olive trees. In vitro inhibitory effects of different concentrations were assessed. Inhibition of conidium germination is important because conidia are important for propagation of the disease.

HTE1 was the most effective treatment against mycelium growth and conidium germination of $V$. dahliae. The diameters of $V$. dahliae colonies decreased with increasing concentrations of this extract. At the tested concentrations, low antifungal effects of HTyr were detected, but greater inhibition was detected from HTE1 and HTE2 at the same relative concentrations of HTyr. HTE1 at $1 \mathrm{mg} \mathrm{mL}^{-1}$ gave greater inhibition of fungal growth than HTE2 or HTyr. However, even greater inhibition was achieved for $V$. dahliae conidium germination. Applying $1 \mathrm{mg} \mathrm{mL}^{-1}$ of HTyr, differences between HTE1 and HTE2 were detected. Similarly, significant differences between HTyr and HTE1 were observed for inhibition of conidium germination., However, no differences were noted between HTE2 and HTyr. The effects of $1 \mathrm{mg} \mathrm{mL}^{-1}$ of HTyr on conidium germination gave better results than detected for inhibition of growth of fungal colonies.

The results are similar to those of previous studies on HTyr enriched extracts from olive mill wastewater (OMWW) that were tested against the olive bacterium pathogens Pseudomonas savastanoi pv. savastanoi (Pss) and Agrobacterium tumefaciens (At) (Caracciolo et al., 2019; Pannucci et al., 2019). In those studies, HTE1 was also the most active extract, which completely inhibited the growth of Pss and at $0.5 \mathrm{mg} \mathrm{mL}^{-1}$ and at $1.0 \mathrm{mg}$ $\mathrm{mL}^{-1}$, compared to untreated controls. In contrast, HTyr 
at $1.0 \mathrm{mg} \mathrm{mL}^{-1}$ only reduced bacterium growth. We have verified that HTyr and HTE1 as antifungal agents produced similar results. This provides results that can be explored in the future, which may provide mechanism of action relating to interactions of these compounds with specific bacterium or fungus cell membranes. Yangui et al. (2010) observed a severe reduction numbers of viable conidia of $V$. dahliae by at least $15 \mathrm{~g} \mathrm{~L}^{-1}$ of HTyrrich OMWW or HTyr-rich extract with contact times greater than or equal to $30 \mathrm{~min}$, or at $12.5 \mathrm{~g} \mathrm{~L}^{-1}$ with contact time of $60 \mathrm{~min}$. Differently in the present study, we evaluated the inhibitory effects on $V$. dahliae mycelium growth and conidium germination, and the present results were obtained for HTE1 and HTE2 extracts from Italian olive cultivars from different geographical origins (Apulia and Sicily). Furthermore, a different extraction procedure based on membrane technology was used, which gave rise to a different phenolic content profile in the extracts.

For HTyr, HTE1 and HTE2, the greatest inhibition of $V$. dahliae mycelium growth was observed after the first $72 \mathrm{~h}$ of incubation. With longer periods of incubation, growth inhibition was less than that observed after $72 \mathrm{~h}$. Decreasing growth inhibition with increasing incubation time possibly indicates that the active compounds were being metabolized by the fungus. Loss in inhibitory activity, and possibly stimulation of mycelium growth, is consistent with results for other fungi, such as Aspergillus sp. when growing on media containing rutin or quercetin, where the fugus produced an extracellular enzyme that degrades these glycosides (Westlake et al., 1959). In the present study, the extracts may not have inhibited mycelium growth during long incubation periods because of breakdown by $V$. dahliae enzymes.

Concerning the stronger activity of HTE1 and HTE2 observed compared to HTyr, this could be due to a central role of the minor phenolic components in the extracts. Some of these have been shown to have antimicrobial activity when tested singularly. Gallic acid possesses a high antifungal activity against Fusarium solani; the hyphae became collapsed and shrunken after $24 \mathrm{~h}$ incubation (Nguyen et al., 2013). Enriched, purified, but still complex mixtures of phenols could possibly provide multiple modes of action giving rise to synergistic antifungal effects.

Several mechanisms of action have been proposed for the antimicrobial activities of phenolic compounds. Their potency may result from the ability to compromise cell functions and membrane integrity, behaving as surface-active compounds (Yangui et al., 2008). Therefore, alteration of microbe membrane permeability, with the consequent loss of cytoplasmic constituents, could explain phenolic activity against pathogenic fungi (Yangui et al., 2009). The mechanisms by which polyphenols act are not entirely understood. However, results from the present study give evidence that the observed antifungal effects was directly related to the chemical composition of HTE1 and HTE2, and mainly to HTyr content of these extracts.

The present study showed that HTE1 and HTE2 have antifungal activity against $V$. dahliae. However, we consider that they are preliminary, since further research is required, including assessments on more pathogen isolates. In addition, studies of olive trees under field conditions are required to extend knowledge of management of this pathogen with these identified extract compounds. Some researchers have suggested that incorporation of OMWW into soil could be an eco-friendly alternative to soil fumigants for crop protection against $V$. dahliae (El-Abbassi et al., 2017). Nevertheless, safe use of OMWP for efficient plant disease control, without negative effects on cultivated crops and soils, remains a challenge. It is also necessary to demonstrate that the phenolic contents of OMWP retains biocidal activity after large-scale applications, allowing sustainable agroeconomic development.

\section{ACKNOWLEDGEMENTS}

This research was supported by "Agroalimentare e Ricerca” (AGER), Project AGER2-Rif.2016-0169: Valorization of Italian olive products through innovative analytical tools (VIOLIN), and by the Italian Ministry for Education, University and Research (MIUR), Project SAFE-Med, Law 232/216, Departments of Excellence.

\section{LITERATURE CITED}

Balouiri M., Sadiki M., Ibnsouda S.K., 2016. Methods for in vitro evaluating antimicrobial activity: A review. Journal of Pharmaceutical Analysis 6: 71-79.

Bernini R., Mincione E., Barontini M., Crisante F., 2008. Convenient synthesis of hydroxytyrosol and its lipophilic derivatives from tyrosol or homovanillyl alcohol. Journal of Agricultural and Food Chemistry 56: 8897-8904.

Bernini R., Mincione E., Barontini M., Crisante F., 2010. Procedimento per la preparazione di derivati dell'idrossitirosolo e di idrossitirosolo. Brevetto N. 0001381959

Bernini R.; Gilardini Montani M. S.; Merendino N.; Romani A. Velotti F. 2015. Hydroxytyrosol-derived 
compounds: a basis for the creation of new pharmacological agents for cancer prevention and therapy. Journal of Medicinal Chemistry 58: 9089-9107.

Bernini R., Carastro I., Palmini G., Tanini A., Zonefrati R.,... Romani A., 2017. Lipophilization of hydroxytyrosol-enriched fractions from Olea europaea L. byproducts and evaluation of the in vitro effects on a model of colorectal cancer cells. Journal of Agricultural and Food Chemistry 65: 6506-6512

Caracciolo R., Pannucci E., Bernini R., Varvaro L., Santi L., 2019. Antibacterial activity of hydroxytyrosolenriched extracts obtained from olive mill waste waters by membrane technologies against olive tree pathogens. 4th International Symposium on Biological Control of Bacterial Plant Diseases. Viterbo. Journal of Plant Pathology vol. 101: 8.

El-Abbassi A., Saadaoui N., Kiai H., Raiti J., Hafidi A., 2017. Potential applications of olive mill wastewater as biopesticide for crops protection. Science of the Total Environment 576: 10-21.

Jiménez-Díaz R.M., Tjamos E.C., Cirulli M., 1998. Verticillium wilt of major tree hosts: olive. A compendium of Verticillium wilts in tree species. Ponsen and Looijen, Wageningen (1998) 13-16.

Jiménez-Díaz R.M., Cirulli M., Bubici G., del Mar Jiménez-Gasco M., Antoniou P.P., Tjamos E.C., 2012. Verticillium wilt, a major threat to olive production: current status and future prospects for its management. Plant Disease 96: 304-329.

Khalil S. K., Shah M. A., Naeem M. (1985). Laboratory studies on the compatibility of the entomopathogenic fungus Verticillium lecanii with certain pesticides. Agriculture, Ecosystems \& Environment 13: 329-334.

Larif M., Zarrouk A., Soulaymani A., Elmidaoui A., 2013. New innovation in order to recover the polyphenols of olive mill wastewater extracts for use as a biopesticide against the Euphyllura olivina and Aphis citricola. Research on Chemical Intermediates 39: 4303-4313.

Lavee S., Rallo L., Rapoport H.F., Troncoso de Arce A., 1996. The floral biology of the olive: effect of flower number, type and distribution on fruitset. Scientia Horticulturae 66(3-4): 149-158.

López-Escudero F.J., Mercado-Blanco J., 2011. Verticillium wilt of olive: a case study to implement an integrated strategy to control a soil-borne pathogen. Plant Soil 344: 1-50.

López-Escudero F.J., Mwanza C., Blanco-López M.A., 2007. Reduction of Verticillium dahliae microsclerotia viability in soil by dried plant residues. Crop Protection 26: 127-133.

Lykas C., Vagelas I., Gougoulias N., 2014. Effect of olive mill wastewater on growth and bulb production of tulip plants infected by bulb diseases. Spanish journal of Agricultural Research: 233-243.

Markakis E.A., Tjamos S.E., Antoniou P.P., Paplomatas E.J., Tjamos E.C., 2016. Biological control of Verticillium wilt of olive by Paenibacillus alvei, strain K165. BioControl 61: 293-303.

Mekki A., Dhouib A., Aloui F., Sayadi S., 2006a. Olive wastewater as an ecological fertiliser.

Mekki A., Dhouib A., Sayadi S., 2006b. Changes in microbial and soil properties following amendment with treated and untreated olive mill wastewater. Microbiological Research 161: 93-101.

Mekki A., Dhouib A., Feki F., Sayadi S., 2008. Assessment of toxicity of the untreated and treated olive mill wastewaters and soil irrigated by using microbiotests. Ecotoxicology and Environmental Safety 69: 488-495.

Mercado-Blanco J., Rodriguez-Jurado D., Hervás A., Jiménez-Diaz R.M., 2004. Suppression of Verticillium wilt in olive planting stocks by root-associated fluorescent Pseudomonas spp. Biological Control 30: 474-486.

Mulero-Aparicio A., Agustí-Brisach C., Varo Á., LópezEscudero F.J., Trapero A., 2019. A non-pathogenic strain of Fusarium oxysporum as a potential biocontrol agent against Verticillium wilt of olive. Biological Control 139: 104045.

Nguyen D.M.C., Seo D.J., Lee H.B., Kim I.S., Kim K.Y.,... Jung W.J., 2013. Antifungal activity of gallic acid purified from Terminalia nigrovenulosa bark against Fusarium solani. Microbial Pathogenesis 56: 8-15.

Pannucci E., Caracciolo R., Romani A., Cacciola F., Dugo P.,... Santi L., 2019. An hydroxytyrosol enriched extract from olive mill wastewaters exerts antioxidant activity and antimicrobial activity on Pseudomonas savastanoi pv. savastanoi and Agrobacterium tumefaciens. Natural Product Research:1-8.

Pizzichini D., Russo C., Vitagliano M., Pizzichini M., Romani A.,... Vignolini P., 2011. Process for producing concentrated and refined actives from tissues and byproducts of Olea europaea with membrane technologies. Pat. No EP2338500A1 29.

Robles-Almazan M., Pulido-Moran M., Moreno-Fernandez J., Ramirez-Tortosa C., Rodriguez-Garcia C., Quiles J.L., Ramirez-Tortosa Mc., 2018. Hydroxytyrosol: bioavailability, toxicity, and clinical applications. Food Research International 105: 654-667.

Romani A., Pinelli P., Ieri F., Bernini R., 2016. Sustainability, innovation, and green chemistry in the production and valorization of phenolic extracts from Olea europaea L. Sustainability 8: 1002.

Thielmann J., Kohnen S., Hauser C., 2017. Antimicrobial activity of Olea europaea Linné extracts and their 
applicability as natural food preservative agents. International Journal of Food Microbiology 251: 48-66.

Triki M.A., Hadj-Taieb S.K., Mellouli I.H., Rhouma A., Gdoura R., Hassairi A., 2012. Identification and screening of bacterial isolates from Saharan weeds for Verticillium dahliae control. Journal of Plant Pathology: 305-311.

Van Alfen N.K., 1989. Reassessment of plant wilt toxins. Annual Review of Phytopathology 27: 533-550.

Varo A., Raya-Ortega M.C., Trapero A., 2016. Selection and evaluation of micro-organisms for biocontrol of Verticillium dahliae in olive. Journal of Applied Microbiology 121: 767-777.

Varo A., Mulero-Aparicio A., Adem M., Roca L.F., RayaOrtega M.C., López-Escudero F.J., Trapero A., 2017. Screening water extracts and essential oils from Mediterranean plants against Verticillium dahliae in olive. Crop Protection 92:168-175.

Westlake D.W.S., Talbot G., Blakley E.R., Simpson F.J., 1959. Microbial decomposition of rutin. Canadian Journal of Microbiology 5: 621-629.

Winkelhausen E., Pospiech R., Laufenberg G., 2005. Antifungal activity of phenolic compounds extracted from dried olive pomace. Bulletin of the Chemists and Technologists of Macedonia 24: 41-46.

Yangui T., Rhouma A., Gargouri K., Triki M.A., Bouzid J., 2008. Efficacy of olive mill waste water and its derivatives in the suppression of crown gall disease of bitter almond. European Journal of Plant Pathology 122: 495-504

Yangui T., Dhouib A., Rhouma A., Sayadi S., 2009. Potential of hydroxytyrosol-rich composition from olive mill wastewater as a natural disinfectant and its effect on seeds vigour response. Food Chemistry 117: 1-8.

Yangui T., Sayadi S., Gargoubi A., Dhouib A., 2010. Fungicidal effect of hydroxytyrosol-rich preparations from olive mill wastewater against Verticillium dahliae. Crop Protection 29: 1208-1213. 